\title{
Endoskopowe leczenie olbrzymich kostniaków podstawy czaszki
}

\author{
Endoscopic treatment of giant skull base osteomas \\ Oleś Krzysztof, Stręk Paweł, Wiatr Maciej, Składzień Jacek, Tomik Jerzy, \\ Morawska Agnieszka, Szaleniec Joanna
}

Otolaryngol Pol 2011 65 (6): $410-413$

\section{SUMMARY}

Introduction: Osteomas are relatively common, benign, slow-growing neoplasms. Mainly occurring in frontal and ethmoid sinuses. Endoscopic surgery plays an important role in management of ethmoid, sphenoid and frontal osteomas.

Aim: We discuss our experiences in endoscopic treatment of giant osteomas. Results: In giant osteomas Draf III or Lothrop approaches are prefered. Periostium of the orbit was intact in all cases. Discharge of cerebrospinal liquid was not observed.

Conclusions: Size of tumor determines type of surgical aprroach. Endoscopic surgery is more and more popular way in surgical treatment of giant osteomas. Hasła indeksowe: guzy podstawy czaszki, kostniaki, minimalnie inwazyjna chirurgia endoskopowa, zatoki przynosowe

Key words: skull base tumors, osteomas, minimally invasive endoscopy, paranasal sinuses

\author{
Cby Polskie Towarzystwo Otorynolaryngologów \\ - Chirurgów Głowy i Szyi \\ Otrzymano/Received \\ 10.03.2011 \\ Zaakceptowano do druku/Accepted \\ 02.04.2011 \\ Katedra i Klinika Otolaryngologi \\ Collegium Medicum \\ Uniwersytetu Jagiellońskiego $w$ Krakowie \\ Kierownik: Prof. dr hab. med. J. Skladzień \\ Wkład pracy autorów/Authors contribution: \\ Wg kolejności \\ Konflikt interesu/Conflicts of interest: \\ Autorzy pracy nie zglaszają konfliktu interesów. \\ Adres do korespondencji/ \\ Address for correspondence: \\ imię i nazwisko: Krzysz tof Oleś \\ adres pocztowy: \\ Katedra i Klinika Otolaryngologii \\ Uniwersytet Jagielloński \\ Collegium Medicum \\ ul. Sniadeckich 2 \\ 31-531 Kraków \\ tel. $(+12)$ 424-79-00 \\ fax $(+12)$ 424-79-25 \\ e-mail olokrista@op.pl
}

\section{Wstęp}

Kostniaki są relatywnie rzadkimi, wolno rosnącymi guzami pochodzenia łącznotkankowego [1-6]. Należą do najczęściej spotykanych guzów łagodnych zatok przynosowych.

W obrębie twarzoczaszki najczęściej występuja w zatokach czołowych i sitowych, zwykle w okolicy przewodu nosowo-czołowego, wyrastając ze szwów kostnych [7]. Bardzo rzadko, w około 5\%, występują w zatoce szczękowej, a wyjątkowo zlokalizowane są w zatoce klinowej. Zwykle nie dają objawów i są przypadkowo rozpoznawane w około $1 \%$ radiogramów tej okolicy.

Większość kostniaków ma rozmiar ok. $5 \mathrm{~mm}$ i jest asymptomatyczna. Duże guzy powyżej $30 \mathrm{~mm}$ średnicy należą do rzadkości, są one przyczyną różnych dolegliwości zgłaszanych przez chorych. Obserwuje się objawy wynikające $z$ zablokowania naturalnych ujść zatok, objawy oczodołowe i wewnatrzczaszkowe.

Chirurgiczna resekcja guzôw powyżej $3 \mathrm{~cm}$ jest możliwa na drodze endoskopowej. Dużym wyzwaniem dla chirurga sa wyjątkowo rzadko spotykane olbrzymie kostniaki, mierzace powyżej $60 \mathrm{~mm}$ [8]. Zwykle mają one szeroką podstawę przyczepu do kości podstawy czaszki, rozlegle zajmują przedni dół czaszki i kompleks nosowo-oczodołowy. Olbrzymie kostniaki wymagaja rozległej resekcji czaszkowo-twarzowej z równoczesną rekonstrukcją tkanek $z$ wykorzystaniem technik mikrochirurgicznych.
Wewnątrzczaszkowe powikłania kostniakôw, takie jak pneumocephalus czy padaczka, są rzadkie.

\section{Cel pracy}

Celem pracy jest przedstawienie doświadczeń własnych w leczeniu olbrzymich kostniakôw leczonych wyłącznie endoskopowo.

\section{Material i metody}

Dokonano retrospektywnej analizy dokumentacji medycznej chorych operowanych endoskopowo $z$ powodu olbrzymich kostniakôw zatok przynosowych w Klinice Otolaryngologii Collegium Medicum Uniwersy tetu Jagiellońskiego w Krakowie w latach 2003-2010.

Przedstawiamy dwóch pacjentów z olbrzymimi kostniakami czołowo-sitowymi powodującymi wzmożenie ciśnienia wewnątrzczaszkowe, zaburzenia neurologiczne i okulistyczne, które całkowicie ustąpiły po leczeniu chirurgicznym, endoskopowym.

\section{Wyniki}

Analiza obejmuje 2 mężczyzn w wieku 23 i 32 lata. U pacjentów tych przed zabiegiem wykonano badanie endoskopowe nosa, tomografię komputerową zatok 
przynosowych, badanie rezonansu magnetycznego a w jednym przypadku angio-TK dla wykluczenia patologicznego unaczynienia $z$ zakresu naczyń wewnątrzmózgowych.

Przed zabiegiem chorzy podawali silne bóle głowy, ból w rzucie zatoki, w której znajdował się kostniak. Skarżyli się także na zaburzenia ruchomości gałki ocznej, bóle oczu, padaczkę z towarzyszącymi comiesięcznymi dużymi napadami, wzrost ciśnienia wewnątrzczaszkowego (pacjent 2).

Zabieg przeprowadzano w znieczuleniu ogólnym, w warunkach podciśnienia kontrolowanego. Używano optyk o kącie widzenia $0^{\circ}$ i $30^{\circ}$ na poczatku zabiegu operacyjnego a następnie $45^{\circ} \mathrm{i} 70^{\circ} \mathrm{W}$ trakcie rozwiercania guza wewnątrz zatoki czołowej.

Operację w każdym przypadku rozpoczęto od wykonania frontoethmoidectomii po stronie mniejszego wymiaru guza, a następnie ethmoidectomii po stronie większego wymiaru kostniaka i zajętego oczodołu.

W przypadku kostniaków olbrzymich wykorzystywany jest dostęp wg Draf III lub Lothropa $z$ rozfrag menowaniem kostniaka wiertłem tnacym o średnicy $3,2 \mathrm{~mm}$ i kącie $55^{\circ}$, a następnie $70^{\circ}$, wg zasad techniki piecemeal (Ryc. 1). Usunięte guzy były oceniane histopatologicznie. Ich średnica wynosiła 34-44 mm. Chorych po zabiegu regularnie kontrolowano endoskopowo, radiologicznie i w dwóch przypadkach neurologicznie i okulistycznie.

W żadnym z omawianych przypadków okostna oczodołu nie została uszkodzona. Cech płynotoku nie zaobserwowano. W przypadku 2. pacjenta stwierdzono ubytek tylnej ściany zatoki czołowej, lecz bez przerwania ciągłości opon mózgowo-rdzeniowych. W wykonanym angio-TK cech hiperwaskularyzacji guza ani jego łączności z unaczynieniem tętnic wewnątrzmózgowych nie stwierdzono (Ryc. 2-6).

Obaj pacjenci są wolni od objawów chorobowych w pierwszym przypadku 4 lata, a w drugim 15 miesięcy po wykonanym zabiegu endoskopowym. Objawy występujące przed leczeniem chirurgicznym całkowicie ustapiły po 1 miesiącu od operacji, a leki przeciw padaczkowe odstawiono pacjentowi po kolejnych 12 miesiącach.

\section{Omówienie}

Kostniaki dające objawy najczęściej spotykane są w sitowiu, zachyłku czołowym i zatoce czołowej. Ich dalszy rozwój w kierunku oczodołu i przedniego dołu czaszki może powodować zaburzenia ruchomości gałki ocznej. jej wytrzeszcz, podwójne widzenie, wzrost ciśnienia wewnątrzczaszkowego, padaczkę.

Wskazania do leczenia chirurgicznego kostniakôw wynikaja z ekspansywnego wzrostu guza, zwłaszcza gdy przekracza on granice zatoki, szybkiego wzrostu lub blokady naturalnych ujść zatok przynosowych.

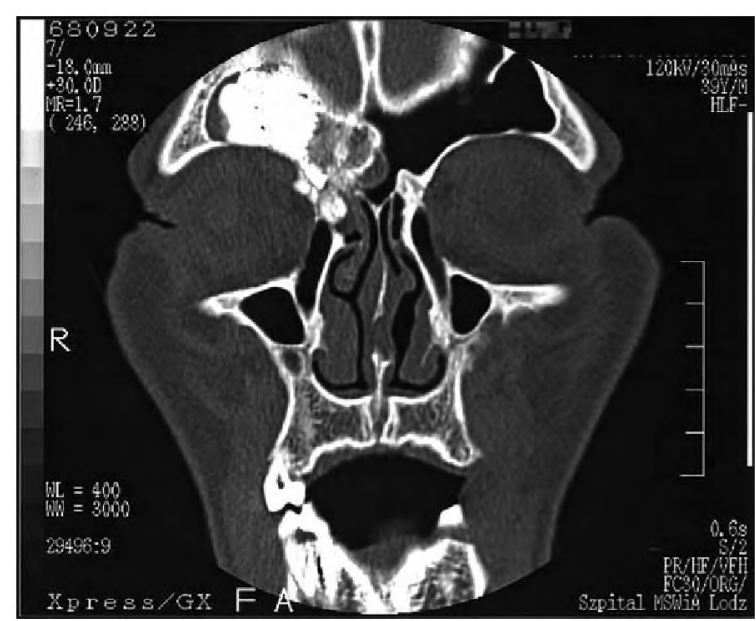

Ryc. 1. Olbrzymi kostniak prawej zatoki czolowej TK - plaszczyzna przednio-tylna

Fig. 1. Giant osteoma of the right front al sinus; CT - A-P plane

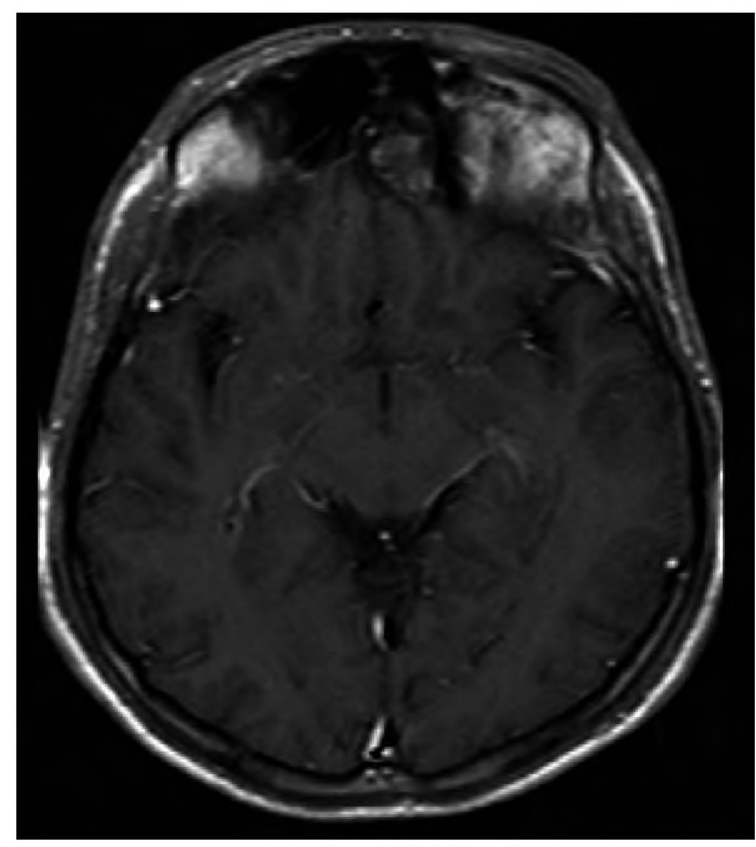

Ryc. 2. Kostniak lewej zatoki czołowej; MRI - plaszczyzna poprzeczna

Fig. 2. Osteoma of the left front sinus; MRI-horizontal plane

Nawroty prawidłowo usuniętych kostniaków są rzadkie [9]. Nie ma jednoznacznych wskazań do operacji małych, ,bezobjawowowych" kostniaków. Wydaje się, że obserwacja wraz z kontrolą radiologiczna jest właś ciwym postępowaniem. Należy pamiętać, że często kostniak wzrasta bardzo gwałtownie, powiększając swoją objętość.

Dominującym objawem podawanym przez chorych był ból głowy. Jego natężenie miało związek z rozmiarami guzów. W następnej kolejności pacjenci podawali nawracajace krwawienia $\mathrm{z}$ nosa, zapalenia zatok przy- 


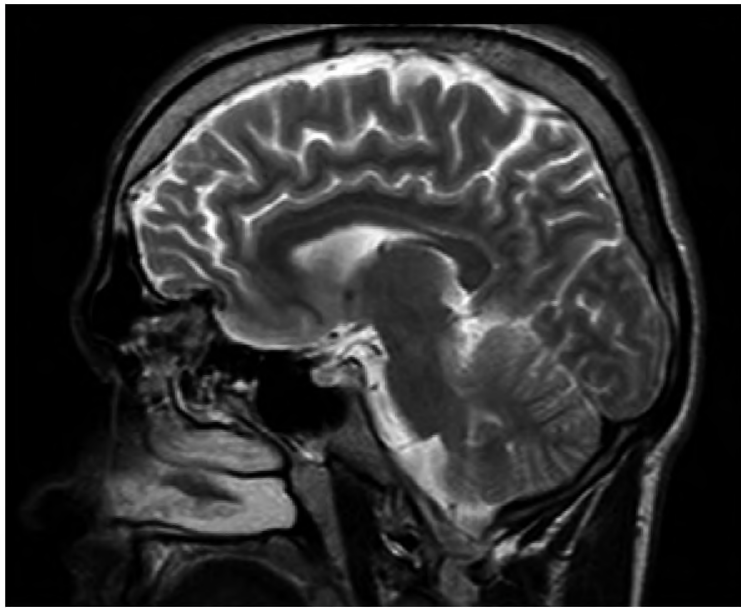

Ryc. 3. Kostniak lewej zatoki czołowej; MRI - plaszczyzna strzałkowa

Fig. 3. Osteoma of the left front sinus; MRI - saggital plane

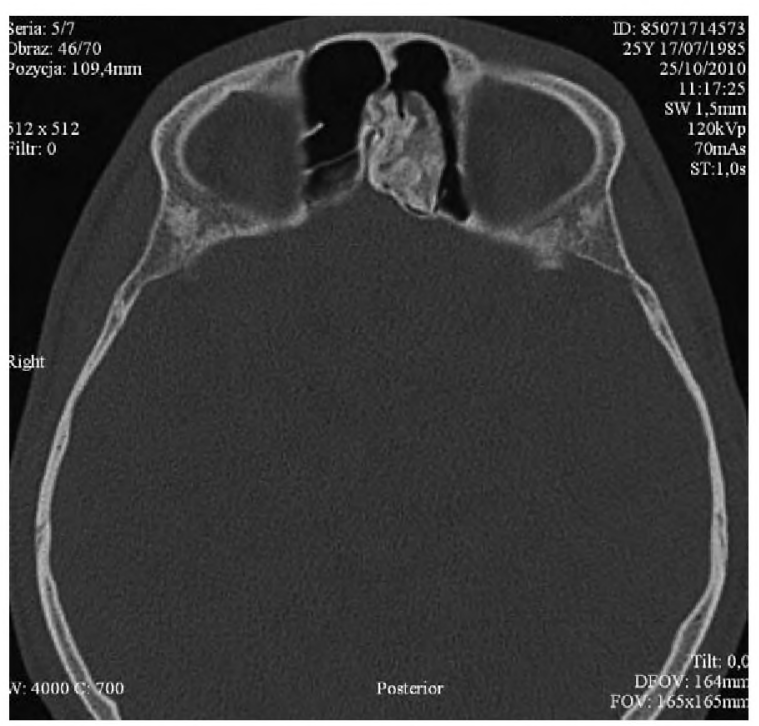

Ryc. 4. Kostniak lewej zatoki czołowej; TK- płaszczyzna poprzeczna

Fig. 4. Osteoma of the left front sinus; CT - horizontal plane

nosowych, ograniczenie ruchomości gałki ocznej, padaczkę. Olbrzymie kostniaki mogą powodować i powodowały u naszych pacjentów destrukcję obramowania kostnego sasiedztwa, w tym przedniego dołu czaszki i oczodołu (pacjent 2). Nie zawsze rozmiar kostniaka decyduje o nasileniu dolegliwości pacjenta, większy wpływ wydaje się mieć lokalizacja guza. Opisywano 40-mm bezobjawowe guzy [10].

Badania obrazowe maja podstawowe znaczenie dla prawidłowego planowania i skutecznego leczenia operacyjnego. Kombinacja CT i MRI pozwala oszacować prawidłowy dostęp do guza. Ma to szczególne znaczenie przy ocenie podstawy czaszki, oczodołu. Przewaga tomografii komputerowej w ocenie stanu ograniczeń kostnych

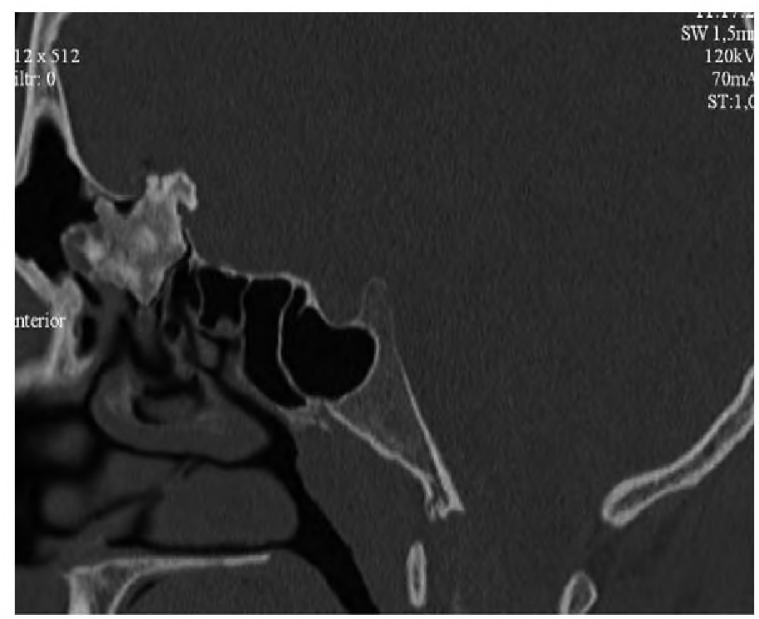

Ryc. 5. Kostniak lewej zatoki czolowej; TK - płaszczyzna strzałkowa

Fig. 5. Osteoma of the left front sinus; CT-saggital plane

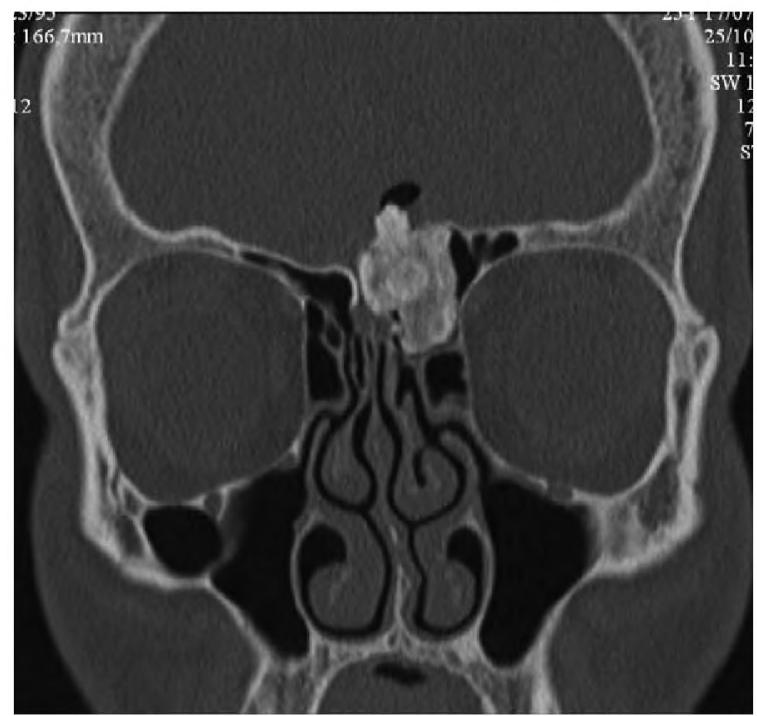

Ryc. 6. Kostniak lewej zatoki czolowej; TK - płaszczyzna przednio-tylna

Fig. 6. Osteoma of the left front sinus; CT-A-P plane

szczególnie blaszki sitowej jest znana. Rola rezonansu magnetycznego jest istotna w ocenie otaczających guz tkanek miękkich, stosunku do opon mózgowo-rdzeniowych, mózgowia i kontroli pooperacyjnych.

Decyzja co do wyboru rodzaju dojścia chirurgicznego zależna jest wielkości guza, jego lokalizacji oraz od doświadezenia operatora. Dojścia chirurgiczne podzielono na zewnętrzne, endoskopowe i skojarzone. Do niedawna bardzo duże kostniaki, zajmujące sąsiednie struktury zatok przynosowych, w tym tylną ścianę zatoki czołowej, uciskające i przemieszczające gałkę oczna, powodujące zaburzenia jej ruchomości były operowane wyłącznie $z$ dojść zewnętrznych, rzadziej skojarzonych. 
W ostatniej dekadzie procedura Draf III jest coraz popularniejsza w leczeniu różnej patologii zatoki czołowej jak przewlekłe stany zapalne czy guzy łagodne. Wybór technik endoskopowych pozwala doskonale wizualizować pole operacyjne, w tym ścianę tylną zatoki czołowej oraz sitowie przednie i obramowanie kostne oczodołu.

Decyzja co do zabiegu operacyjnego zależy od nasilenia dolegliwości bólowych i wzrostu ciśnienia wewnątrzczaszkowego. Większość autorów skłania się do dostępôw zewnętrznych, w tym neurochirurgicznych, w przypadku zajęcia tylnej ściany zatoki czołowej ze względu na grożące komplikacje, w tym wyciek płynu mózgowo-rdzeniowego i następowe powikłania [11, 12].

Autorzy przedstawili przykłady chirurgicznej resekcji olbrzymich kostniaków powyżej $3 \mathrm{~cm}$ na drodze endoskopowej. W piśmiennictwie występują coraz częstsze doniesienia o tej drodze usuwania olbrzymich kostniakôw [13, 14].

W ostatniej dekadzie chirurgia endoskopowa zajmuje coraz większy odsetek wśród metod wybieranych przez chirurgôw do leczenia olbrzymich kostniaków.

\section{Wnioski}

1. Duże kostniaki zatok przynosowych powyżej $30 \mathrm{~mm}$ są rzadkością.

2. Istnieją możliwość usuwania dużych kostniaków drogą chirurgii endoskopowej.

\section{PIŚMIEN N I C T WO}

1. Stręk P, Zagólski O, Składzień J et al.: Endoskopowe leczenie chorych z kostniakami zatok przynosowych - doświadczenia własne. Otolaryngol Pol, 2007;3:260-64.

2. Brodish BN, Morgan CE, Sillers MJ: Endoscopic resection of fibro-osseous lesions of the paranasal sinuses. Am J Rhinol, 1999; 13:111-16.
3. Kim AW, Foster JA, Papay FA et al: Orbital extension of a frontal sinus osteoma in a thirteen-year-old girl. J AAPOS, 2000;4:122-24.

4. Menezes CA, Davidson TM, Endoscopic resection of a sphenoethmoid osteoma: a case report. Ear Nose Throat J, 1994;73:598-600.

5. Mikaelian DO, Lewis WJ, Behringer WH. Primary osteoma of the sphenoid sinus. Laryngoscope 1976;86:728-733.

6. Namdar J, Edelstein DR, Huo $J$ et al: Management of osteomas of the paranasal sinuses. Am J Rhinol, 1998; 12:393-398.

7. Sente M, Topolac R, Peic-Gavran $\mathrm{K}$ et al: Frontal sinus osteoma as a cause of purulent meningitis. Med Pregl, 1999;52:169-172.

8. Bushan B, Watal G, Ahmed A et al: Giant ivory osteoma of frontal sinus. Australas Radiol, 1987;31:306-8.

9. Boysen M, Osteomas of the paranasal sinuses. J Otolaryngol, 1978:366-70.

10. Castelnuovo P, Giovannetti F, Bignami M et al: Open surgery versus endoscopic surgery in benign neoplasm involving the frontal sinus. J craniofac Surg. 2009;20:180-3.

11. Gungor A, Sali M, Kutlay M et al: A case of giant frontal sinis osteoma. Kulak Burun Bogaz Ihtis Derg, 2003; 10:163-66.

12. Carbonell J, Olabe J, Lopez A et al: Intracranial hypertension syndrome due to giant frontoethmoidal osteoma. Acta Otorrinolaringol ESP, 1996;475: 397-400.

13. Haddad FS, Haddad GF, Zaatari G. Cranial osteomas: Their classification and management. Report on a giant osteoma and review of the literature. Surg Neurol, 1997;48:143-7.

14. Chiu AG, Schipor I, Cohen NA et al.: Surgical decisions in the management of frontal sinus osteomas. Am J Rhinol, 2005; 19:191-7. 